\title{
A CURIOSIDADE DENEGADA: QUANDO A INFÂNCIA NEGLIGENCIADA FAVORECE O RISCO AO ABUSO SEXUAL
}

\author{
CURIOSIDAD DENEGADA: CUANDO LA INFANCIA DESCUIDADA FAVORECE EL \\ RIESGO DE ABUSO SEXUAL
}

\section{DENEGED CURIOSITY: WHEN NEGLECTED CHILDHOOD FAVORS THE RISK OF SEXUAL ABUSE}

\author{
Artur Augusto Fernandes Leão NETO ${ }^{1}$ \\ Jéssica da Costa JACINTO ${ }^{2}$ \\ Ricardo DESIDÉRIO ${ }^{3}$
}

RESUMO: Para o presente trabalho adotamos a metodologia de análise a partir de bibliografia sobre o abuso sexual infantil, tema que encerra em si mesmo a ambivalência de ser tabu e urgente. Tabu, por ser proibido e cercado de segredos, discriminação, preconceito e urgente, pois se faz necessária a disponibilização de espaços adequados, éticos e cientificamente respaldados, dada a crescente e acentuada ocorrência deste modo de violação e violência contra a infância. Temos por objetivo analisar a importância de uma Educação Sexual infantil e que, seu trabalho na educação escolar se alie como dispositivo ${ }^{4}$ legitimado e socialmente responsável como contribuição ao enfrentamento do abuso sexual infantil.

PALAVRAS-CHAVE: Educação. Sexualidade. Infância. Violência. Enfrentamento.

RESUMEN: Para el presente trabajo adoptamos la metodología de análisis basada en una bibliografía sobre abuso sexual infantil, tema que contiene en sí mismo la ambivalencia de ser tabú y urgente. Tabú, por estar prohibido y rodeado de secretos, discriminación, prejuicio y urgencia, ya que es necesario brindar espacios adecuados, éticos y sustentados cientificamente, dada la creciente y acentuada ocurrencia de esta modalidad de violación y violencia contra los niños. Nuestro objetivo es analizar la importancia de la Educación Sexual

${ }^{1}$ Universidade Estadual Paulista (UNESP), Araraquara - SP - Brasil. Mestrando no Programa de Pós-graduação em Educação Sexual. Pesquisador do NuSex (Núcleo de Estudos em Sexualidade). ORCID: https://orcid.org/00000002-4260-2654. E-mail: fernandesleaopsico@gmail.com

${ }^{2}$ Universidade Estadual Paulista (UNESP), Araraquara - SP - Brasil. Mestranda Mestrando no Programa de Pósgraduação em Educação Sexual. Membro Grupo de Pesquisa em Educação e Diversidade (GPED/UNESPAR). Diretora voluntaria e fundadora da ONG Núbia Rafaela Nogueira. Bolsista FAPESP. ORCID: https://orcid.org/0000-0002-6192-0754. E-mail: costa.jacinto@unesp.br

${ }^{3}$ Universidade Estadual Paulista (UNESP), Araraquara - SP - Brasil. Docente no Programa de Pós-graduação em Educação Sexual, Pesquisador nos Grupos Sexualidade Vida/USP-CNPq, EDUSEX-Formação de Educadores e Educação Sexual (UDESC) e Grupo de pesquisa sobre educação e sexualidade- GEPEX (UNIOESTE). Doutorado em Educação Escolar (UNESP). ORCID: https://orcid.org/0000-0003-2779-2696. E-mail: contatodesiderio@hotmail.com

${ }^{4}$ Um conjunto decididamente heterogêneo que engloba discursos, instituições, organizações arquitetônicas, decisões regulamentares, leis, medidas administrativas, enunciados científicos, proposições filosóficas, morais, filantrópicas. Em suma, o dito e o não dito são os elementos do dispositivo. O dispositivo é a rede que se pode tecer entre estes elementos (FOUCAULT, 2000, p. 244).

RPGE- Revista on line de Política e Gestão Educacional, Araraquara, v. 24, n. esp. 3, p. 1713-1726, dez. 2020. e-ISSN:1519-9029 
Infantil y que su labor en la educación escolar se alie como un dispositivo legítimo y socialmente responsable como un aporte a la lucha contra el abuso sexual infantil.

PALABRAS CLAVE: Educación. Sexualidad. Infancia. Violencia. Albardilla.

ABSTRACT: For this work, we adopted the analysis methodology based on a bibliography on child sexual abuse, a theme that contains within itself the ambivalence of being taboo and urgent. Taboo, for being prohibited and surrounded by secrets, discrimination, prejudice and urgent, since it is necessary to provide adequate spaces, ethical and scientifically supported, given the growing and accentuated occurrence of this mode of rape and violence against children. We aim to analyze the importance of Child Sexual Education, so that its work in school education is combined with a legitimate and socially responsible device as a contribution to the fight against child sexual abuse.

KEYWORDS: Education. Sexuality. Childhood. Violence. Coping.

\section{Introdução}

Ao longo dos anos, várias ações foram realizadas para se consolidar um instrumento de proteção e enfrentamento as mais variadas formas de violência infantil, incluindo nessa gama de possibilidades o abuso sexual e a exploração sexual de crianças e adolescentes. A violência sexual trata-se de um crime contra a dignidade humana, sendo uma questão complexa que a sociedade em geral ainda não conseguiu sanar. Vale ressaltar que temos leis e legislações prevista para nortear o trato com crianças e adolescentes, ter conhecimento desses dispositivos legais pode contribuir para aprimorar a rede de proteção de enfrentamento à violência sexual e a exploração sexual infantil. Para se compreender a problemática do assunto temos que adentrar em uma perspectiva histórica acerca da forma como a sociedade brasileira vê e trata crianças e adolescentes (SANTOS, 2011).

A legislação brasileira pode ser um instrumento de combate à violência sexual, assim compreendemos a importância de ter uma base consolidada na esfera jurídica no que refere aos mecanismos de enfrentamento a violência. No Brasil as movimentações sociais e políticas acerca da proteção a crianças e adolescentes começaram a ganhar notoriedade em meados de 1988, entretanto já havia pressão internacional para um melhor tratamento da infância, legislações foram criadas a fim de melhor esclarecer quais seriam os direitos de crianças e adolescentes.

Destacando-se a Declaração dos Direitos humanos de 1948, embora o texto não traga a especificidade da criança, ele afirma a seguinte posição em seu Art 5\%, "Ninguém será submetido à tortura nem a tratamento ou castigo cruel, desumano ou degradante" (BRASIL, 
1948). Embora a declaração não tenha um valor de lei geral, ela possui uma carga política que é levada em consideração, tendo em vista o histórico que propiciou a necessidade de sua criação.

Ainda em âmbito internacional, precisamente dez anos após a promulgação da declaração dos direitos humanos, é criada em 1959 a declaração dos direitos da criança, documento este que versa acerca da proteção de crianças e adolescentes, em seu princípio $9^{\circ}$ destaca se o seguinte apontamento, “A criança gozará proteção contra quaisquer formas de negligência, crueldade e exploração. Não será jamais objeto de tráfico, sob qualquer forma [...]" (BRASIL, 1990). Ilude-se quem acha que existência de leis e declarações acerca dos direitos a infância da juventude são o suficiente para deter a cultura de violência instituída pela sociedade ao longo do seu percurso histórico. Embora tais documentos sejam importantes para ressaltar o respeito e dignidade na juventude, temos que ponderar, se existe uma declaração é um instrumento de proteção elaborado pelo Estado para a proteção de crianças e adolescentes isso é resultado de anos de negligência para com a infância. Ainda sob a luz da Declaração dos Direitos da Criança o princípio $2^{\circ}$ estabelece que

a criança gozará proteção especial e ser-lhe-ão proporcionadas oportunidades e facilidades, por lei e por outros meios, a fim de lhe facultar o desenvolvimento físico, mental, moral, espiritual e social, de forma sadia e normal e em condições de liberdade e dignidade. Na instituição de leis visando este objetivo levar-se-ão em conta, sobretudo, os melhores interesses da criança [...] (BRASIL, 1990).

Posterior em 1989 temos como destaque a convenção dos direitos da criança, trata-se um documento firmado pelos países que pertenciam a ONU no ano de 1989, representando um avanço no que refere a um subsídio legal que versa acerca da violência sexual.

Os estados Partes adotarão todas as medidas legislativas, administrativas, sociais e educacionais apropriadas para proteger a criança contra todas as formas de violência física ou mental, abuso ou tratamento negligente, maus tratos ou exploração, inclusive abuso sexual, enquanto a criança sob custódia dos pais, do representante legal ou de qualquer outra pessoa responsável por ela. Essas medidas de proteção deveriam incluir, conforme apropriado, procedimentos eficazes para a elaboração de programas sociais capazes de proporcionar uma assistência adequada à crianças e às pessoas encarregadas de seu cuidado, bem como para outras formas de prevenção, para a identificação, notificação, transferência a uma instituição, investigação, tratamento e acompanhamento posterior dos casos acima mencionados de maus-tratos à criança e, conforme o caso, para intervenção judiciária [...]

Os Estados partes se comprometem a proteger a criança contra todas as formas de exploração e abuso sexual. Nesse sentido os Estados Partes tomarão, em especial, todas as medidas de caráter nacional, bilateral e multilateral que sejam necessárias para impedir 
a) $\mathrm{O}$ incentivo ou a coação para que a criança dedique-se a qualquer atividade sexual ilegal

b) A exploração da criança na prostituição ou outras práticas sexuais ilegais

c) A exploração da criança em espetáculos ou materiais pornográficos (BRASIL, 1990 Art. 19, 34).

No Brasil, no ano de 1988, ela é sancionada pelo então Presidente da República a Constituição Federal, o documento traz em seu texto uma importante contribuição jurídica, o texto sugere recomendações para o tratamento da infância e da responsabilização do cuidado dessa categoria de forma abrangente, tendo em vista que isso está em consonância com os demais documentos internacionais elaborados e aqui apresentados. Dessa forma na Constituição é evidente que

Art. 227 - é dever da família, da sociedade e do Estado assegurar à criança, e ao adolescente e ao jovem, com absoluta prioridade, o direito à vida, à saúde, à alimentação, à educação, ao lazer, à profissionalização, à cultura, à dignidade, ao respeito, liberdade e à convivência familiar e comunitária, além de colocá-los a salvo de toda a forma de negligência, discriminação, exploração, violência, crueldade e opressão (BRASIL, 1988).

Posterior a criação de Constituição Federal, temos a elaboração do Estatuto da criança e do adolescente (ECA), que sucedeu o antigo Código Mello de Matos que vigorava até então como um conjunto de normas e condutas para com o trato de crianças e adolescentes, ressaltando ainda que este era alvo de constante críticas pelo seu caráter opressor e punitivo sendo conhecimento a Doutrina de Proteção Irregular, visto que o mesmo só se preocupava em punir os delitos cometidos pelos "menores infratores". Após a criação do ECA se consolidou a Doutrina Integral que se tornou referência internacional de proteção a crianças e adolescentes. Fruto de uma aliança de diversos setores públicos, concomitante aos interesses da Sociedade Civil e com a colaboração de diversos especialistas, o ECA resinificou e expandiu o princípio de "proteção" integral de crianças e adolescentes. Em seu Art. 5 especifica que "Nenhuma criança ou adolescente será objeto de qualquer forma de negligência, discriminação, exploração, violência, crueldade, opressão, punido na forma lei, qualquer atentado, por ação ou omissão, aos seus direitos fundamentais" (BRASIL, 1990).

\section{Metodologia}

Para elaboração deste artigo acadêmico partimos da análise qualitativa "[...] a abordagem qualitativa aprofunda-se no mundo dos significados das ações e relações humanas, 
um lado não perceptível e não captável em equações, médias e estatísticas" (MINAYO, 2003, p. 22). Realizamos um levantamento da bibliografia, pois "a pesquisa bibliográfica compreende: a escolha do assunto, elaboração do plano de trabalho, identificação, localização, compilação, fichamento, análise e interpretação, redação” (MEDEIROS, 2000, p. 40-42). Levantamos estudos realizados que tivessem como tema a educação, sexualidade, gênero e violência contra a criança. Deste modo, reconhecemos que tanto na legislação vigente como em trabalhos acadêmicos, estes temas, nos últimos anos, são amiúde de interesse dos mais diversos profissionais e pesquisadores proporcionando a possibilidade de se entendê-los sob várias óticas, confirmando a atualidade do tema, justificando nosso interesse pelas temáticas, especialmente, partindo da violência contra a criança e enleando suas muitas intersecções com as outras acima elencadas.

\section{Desenvolvimento}

Curiosidade, este substantivo feminino cuja substância é, segundo o site Dicio, a "qualidade do que tem grande vontade de saber, de conhecer algo novo ou desconhecido", esta importante força motriz das e para as habilidades humanas tem sido cada vez mais disciplinada, não no sentido de uma educação escolar voltada à formação de pessoas autônomas e cônscias de sua responsabilidade social, mas, antes, ao condicionamento pelo material didático e pelos interesses do projeto político-pedagógico institucional. Em outras palavras, o reconhecimento da curiosidade como catalizadora do processo de aprendizagem é diretamente proporcional à sua conformação ao projeto didático escolar. Isto se configura em um cerceamento do movimento espontâneo da criança em direção ao mundo, na descoberta do mundo, da sociedade na qual se inscreve, analogamente retratada no espaço coletivo da escola e, também, no entendimento de si como protagonista parte de sua relação com as performatividades ${ }^{5}$ e discursividades $^{6}$ dos agentes escolares (de todos os profissionais da escola, da faxina à direção, especialmente, os professores, com quem passam a maior parte de seu tempo na escola) embora

${ }^{5}$ Em outras palavras, atos, gestos e desejo produzem o efeito de um núcleo ou substância interna, mas o produzem na superfície do corpo, por meio do jogo de ausências significantes, que sugerem, mas nunca revelam, o princípio organizador da identidade como causa. Esses atos, gestos e atuações, entendidos em termos gerais, são performativos, no sentido de que a essência ou identidade que por outro lado pretendem expressar são fabricações manufaturadas e sustentadas por signos corpóreos e outros meios discursivos. $O$ fato de o corpo gênero ser marcado pelo performativo sugere que ele não tem status ontológico separado (BUTLER, 2003, p. 194).

${ }^{6} \mathrm{~A}$ temporalidade da convenção linguística, considerada como ritual, excede o momento de sua expressão, e este excesso não é totalmente captável ou identificável (o passado e o futuro do discurso não podem ser narrados com segurança), portanto evidencia-se que parte do que constitui a "situação total de fala" falha em alcançar forma totalizada em qualquer instância (BUTLER apud GRAÇA, 2016, p. 31). 
não apenas destes - afinal, também são parte de suas relações: núcleos familiares, colegas, amizades, etc. Atentando apenas ao dispositivo escolar, é como se a disponibilidade pedagógica estivesse, a priori, endereçada a ouvir, responder, ensinar, interagir, dar atenção privilegiada ao que não fuja, destoe, rompa com o ideal de comportamento desejado pelos agentes escolares.

Esta 'disponibilidade endereçada' dos educadores acaba por corromper a sutil e, ao mesmo tempo, poderosa relação ensino-aprendizagem, porque hierarquiza em categorias, não apenas as disciplinas e os temas a serem trabalhados, mas também, discrimina 'quem é quem' no corpo discente. Neste voluntarioso exercício de subsunção, a relação didático-pedagógica está sujeita a deslegitimar a curiosidade espontânea da criança, principalmente, quando esta expõe a insegurança do docente em determinado(s) tema(s) e, ao constrangê-lo, este assume, amiúde, a postura de quem ouve ao modo de não ter escutado, vê ao modo de não ter que enxergar, desvia o assunto ou não responde a contento ao modo de ter respondido, deste modo, denega da curiosidade da criança. Esta realidade evidencia-se muito bem quando o assunto é a sexualidade, considerado tema tabu para muitas pessoas e, também, tratada e/ou exercida com displicência por outras tantas. Maia (2005, p. 121), diz

Toda criança é muito curiosa. Temos a tendência a estimular essa curiosidade quando se trata de assuntos como a natureza, a língua, a história, etc., mas não o fazemos quando se trata de sexualidade. Por quê? Porque este é um assunto que inibe muito os adultos e que eles acham que seria melhor se fosse esquecido! Entretanto, para as crianças, a curiosidade sobre sexo é um fato, já que se trata de um tema que naturalmente desperta a curiosidade $[\ldots]$.

O desconforto de parte considerável dos professores com a temática da sexualidade é tão patente que a saída comumente adotada nas escolas é associar-se o ensino do corpo humano e suas transformações a duas áreas do conhecimento: biologia e educação física. Do ponto de vista pedagógico é evidente esta associação por valerem-se, estes dois campos dos saberes, também, das peculiaridades atinentes à vida, seus desdobramentos, desenvolvimento, reprodução e potencialidades. Ainda, segundo a referida autora,

Questões como o nascimento dos bebês, as diferenças entre meninos e meninas, as sensações provocadas pelo toque nos genitais, ou fatos como o namoro do irmão mais velho e o beijo visto na novela, chamam a atenção da criança que se sente instigada a procurar respostas para suas questões (MAIA, 2005, p. 121).

Respeitadas as distinções oportunas entre elas, que não se confundem, antes, complementam-se, ao menos quanto à espécie humana são responsáveis por observar este mesmo fenômeno do corpo humano por perspectivas importantes, mas que não dão conta desta 
totalidade, por expressar-se, este fenômeno, em outros níveis e subníveis discursivos e performáticos, como o desenvolvimento científico vem comprovando.

Evidencia-se, nos dizeres de Augustuni e Rossi (2015, p. 1624), que pelo concurso dos

autores da educação, sociologia, psiquiatria e psicologia, do fim do século XIX, em seus estudos, tais como Vygotsky, Montessori, Freinet, Freud, dentre outros, já iniciaram uma grande discussão ampliando os conhecimentos acerca dos fatores psíquicos, afetivos, sociais e sexuais para além do aspecto biológico, cada qual com suas peculiaridades[...].

A união entre o racional e o emocional, como o proposto, está na contramão da cultura hegemônica voltada a priorizar o mundo do trabalho, da produção e do consumo, desta forma, forçando a sociedade, pela massificação dos valores pragmáticos e reificadores, a dinamizar-se de modo análogo a um dispositivo mecânico e a escola, como dispositivo referendado à aculturação disciplinada ${ }^{7}$ dos corpos, vê-se impelida a uma lógica semelhante. Ou seja, todo o dispositivo escolar se estrutura em sua organização, didática, recursos, dentre outros, a reproduzir, no sentido mesmo do termo, não só a adequação dos corpos à cultura hegemônica, mas também, como espaço legitimado à manutenção do status quo. Neste sentido, a educação escolar a serviço do interesse de mercado trabalha para condicionamento de capital humano que cumpra, disponível e disciplinado, com as funções a este designadas. Augustuni e Rossi (2015, p. 1629), ajudam a elucidar esta dinâmica assumindo que

Atualmente as escolas não mudaram em quase nada as suas concepções acerca das condutas morais que desejam conquistar, ou melhor, desenvolver coercitivamente em seus alunos. Desse modo, a liberdade de expressão não encontra espaço para manifestar-se, comprometendo a vivência dos prazeres e desejos que poderiam ser experimentados de forma plena, não fosse o condicionamento exercido pela sociedade em busca dos padrões civilizatórios politicamente aceitáveis.

No contexto atual, poucas são as escolas insubordinadas a esta lógica. Não obstante, a educação, que para muito além do espaço e práticas inscritas no interior das instituições, se dá no seio das sociedades, das culturas, das famílias. Desde o nascimento, o bebê já começa a receber os cuidados segundo o repertório simbólico de seus cuidadores. Da manipulação do corpo do bebê às palavras a este direcionadas, das roupas à decoração do quarto, a comunicação, o contato, toda a interação, enfim, o modus vivendi experienciado com este novo ser e membro do núcleo familiar se dá conforme o repertório simbólico referente a este mesmo novo ser. Lucifora, Reina, Muzzeti e Silva (2005, p. 1397-1398), escrevem que

${ }^{7}$ Idem nota 4.

RPGE- Revista on line de Política e Gestão Educacional, Araraquara, v. 24, n. esp. 3, p. 1713-1726, dez. 2020. e-ISSN:1519-9029 
Gomes (2006) assume o Habitus como o aprendizado que ocorre desde os primeiros momentos da vida, podendo iniciar-se antes mesmo do nascimento do sujeito, com as aspirações sociais que se formam partindo da descoberta do sexo do bebê. A instituição familiar com seus valores e crenças constroem comportamentos positivos e negativos desde a primeira infância, utilizandose de meios sutis e refinados nas naturalizações que impregnam o habitus primário.

Nas palavras de Fernandes, Reina e Mokwa (2005, p. 1666)

A partir do momento em que uma mulher engravida, inicia-se uma Educação Sexual com a ansiedade em distinguir o sexo, [em] princípio. Após essa definição, cria-se um mundo das possibilidades como o nome a ser dado, a cor do quarto, a aparência, enfim, uma nova vida já previamente, definida, ou melhor dizendo, hétero-normativamente definida.

Há modelos pré-estabelecidos de decoração para meninas e para meninos. As cores, os temas dos desenhos animados, os brinquedos, a forma como educar cada gênero, a princesa e o "macho garanhão", ainda se perpetua no nosso século.

Ainda por estes mesmos autores (FERNANDES; REINA; MOKWA 2005, p. 1667) é possível entendermos de maneira análoga que o modus vivendi, ao qual nos referimos e do qual o repertório simbólico é imanente, encontra no habitus de Bourdieu (2007) apropriada expressão, porque

O habitus, produto de uma aquisição histórica, é o que permite a apropriação do legado histórico. [...] O herdeiro herdado, apropriado à herança, não tem necessidade de querer, isto é, de deliberar, escolher e decidir conscientemente, para fazer o que é apropriado, o que convém aos interesses da herança, de sua conservação e de sua ampliação. A rigor, ele pode nem saber o que faz ou o que diz e, não obstante, acabar fazendo ou dizendo exatamente conforme as exigências de perpetuação da herança.

Ou seja, as performatividades e discursividades inscritas numa determinada cultura encontrarão mais imediato desenvolvimento nesta mesma cultura na qual se inscrevem. Este fenômeno da aculturação tem na sociedade midiatizada múltiplos recursos possíveis de serem utilizados para acessar o maior número de pessoas e sem necessariamente estar limitada às fronteiras ou limites territoriais quando conectada à internet. A facilidade de acesso à cultura ou, melhor, às culturas, virtualmente ilimitado, favorece o contato, real e/ou virtual, com as muitas faces dela mesma e em sua pluralidade. Facilidade de acesso à pluralidade das muitas faces da cultura, entendida como produto e convenientemente viabilizada pelo interesse mercadológico, expõe esta mesma sociedade à cultura de massa, de consumo rápido e sem maiores exigências intelectuais para sua apreciação. 
$\mathrm{Na}$ vida cotidiana de uma cultura ainda profundamente marcada desde o seu nascimento colonial pelo machismo, sexismo, misoginia e pelo racismo, temos como um dos resultados possíveis o que muito bem nos colocam Lucifora, Reina, Muzzeti e Silva (2005, p. 1396-1397) quando refletem

sobre como as desigualdades de gênero se reinventam social e culturalmente de forma que muitas vezes assumem estratégias ideológicas tão fortes que impossibilitam seu reconhecimento facilmente. [...].

Estudos na área da educação, cultura e sociedade apontam um contexto desigual no Brasil, no que diz respeito às relações entre os gêneros e, que se iniciando na formação familiar, acaba avançando por diversas outras instituições como escola, igreja, hospital, mídia etc., que seguem podando relações mais justas e igualitárias entre os diferentes sujeitos.

Gonini e Ribeiro (2014) nos apontam, na historiografia da Educação Sexual no Brasil, que pesa sobre as relações neste contexto um machismo exacerbado e naturalização da submissão feminina. É possível reconhecer diversas formas de subjugação das mulheres, o que eclode em um alta taxa de violência contra a mulher e diversas justificativas sociais como se estas fossem merecedoras de tal violência. Muitas são as notícias diárias de mulheres sofrendo abusos sexuais por estranhos e parentes, sendo agredidas por seus parceiros ou por dizerem um não para um homem, pelo que vestem, pelo trabalho que exercem e diversos outros motivos que as colocam em situação de insegurança e sofrimento.

A mesma cultura capaz de produzir em seu seio as muitas faces do machismo e seus desdobramentos, também é capaz de produzir o femismo em cujos desdobramentos está seu significado, a saber: antônimo do machismo no sentido, agora, das mulheres contra os homens, opressão operada contra os homens. Essa aparente reversão do quadro social, mesmo que circunstancial e pontualmente, foi rapidamente assimilada pela indústria cultural sob a máscara de reparação histórica, e proposta como sua legitimidade sendo diretamente proporcional à similitude com a opressão sofrida pelos corpos femininos ao longo do tempo. Este fenômeno do femismo não encontra respaldo nem paralelo com o feminismo para o qual o empoderamento dos corpos femininos está na reparação histórica pautada pela equidade dos gêneros em todos os campos das relações sociais e humanas. Na música, desenhos animados, seriados, filmes etc., é possível encontrarmos muitos destes exemplos cujas protagonistas femininas demonstram desenvolvimentos similares aos de protagonistas masculinos. As artes nos favorecem o contato com o dinamismo sociocultural entranhado às sociedades nas quais são desenvolvidas.

Acontece que este dinamismo é ao mesmo tempo causa e consequência do tensionamento do tecido social, de fato, se nos apresenta como violência, comumente extravasando o campo simbólico e se materializando em muitas performatividades e 
discursividades que reiteram o status quo muito bem colocadas por Bourdieu (2014) (apud LUCIFORA; REINA; MUZZETI; SILVA, 2005, p. 1398-1402)

As divisões constitutivas da ordem social e, mais precisamente, as relações sociais de dominação e de exploração que estão instituídas entre os gêneros se inscrevem, assim, progressivamente, em duas classes de habitus diferentes, sob a forma de hexis corporais opostos e complementares e de princípios de visão e de divisão, que levam a classificar todas as coisas do mundo e todas as práticas segundo distinções redutíveis entre o masculino e o feminino.

A dominação masculina encontra assim reunidas todas as condições de seu pleno exercício. A primazia universalmente concedida aos homens se afirma na objetividade de estruturas sociais e de atividades produtivas, baseadas em uma divisão sexual do trabalho de produção e de reprodução biológica e social, que confere aos homens a melhor parte, bem como nos esquemas imanentes a todos os habitus moldados por tais condições, portanto objetivamente concordes, eles funcionam como membros da sociedade, como transcendentais históricos que sendo universalmente partilhados, impõem-se a cada agente como transcendentes.

E ainda nas palavras de Bourdieu (2007 apud FERNANDES; REINA; MOKWA, 2005,

p. 1668-1669)

Quando os poderes estão desigualmente distribuídos, em vez de se mostrar como um universo de possíveis igualmente acessíveis a todo o sujeito - postos a ocupar, estudos a fazer, mercados a conquistar, bens a consumir, propriedades a trocar, etc. -, o mundo econômico e social se apresenta como universo balizado, semeado por injunções e proibições, por signos de apropriação e exclusão, por sentidos obrigatórios ou barreiras intransponíveis, numa palavra, profundamente diferenciado, sobretudo conforme o grau em que propõe oportunidades estáveis e de molde a favorecer e a preencher expectativas estáveis. Sob suas diferentes espécies, o capital é um conjunto de direitos de preempção sobre o futuro, garante a alguns o monopólio de certos possíveis que, no entanto, encontram-se oficialmente garantidos a todos (como o direito à educação).

Subestimamos a educação quando acreditamos estar circunscrita, em seu saber-fazer, ao ambiente institucional. No entanto, é neste campo do pedagógico como processo educacional refletido que reside extraordinário manancial a ser explorado nos mais diversos setores do conhecimento humano, e a sexualidade faz parte deste inesgotável arcabouço. Sabemos que a aprendizagem é tão mais eficiente quanto significativo é o saber a ser experienciado e os modos dessa experiência favorece a inteligibilidade da pessoa aprendiz. Lucifora, Reina, Muzzeti e Silva (2005, p. 1397), nos esclarecem ser

Necessário refletir sobre as bases que ancoram este contexto sexista e dessa forma clarificar as construções simbólicas marcadas pelo sexo dos sujeitos, que seguem como arbitrárias ao longo de suas vidas. Homens e mulheres são 
construídos de forma[s] distintas desde que são reconhecidos enquanto sexo; as construções são reforçadas ao longo da vida, formando um reconhecimento social e uma naturalização com uma delimitação muito bem definida.

A ideologia dominante cuida de naturalizar as relações como se estas fossem organicamente distintas entre homens e mulheres; aquilo que por força de uma manutenção social iniciada na família e reforçada por outras instituições mantém-se ao longo da história e na cultura como um dado biológico inerente aos indivíduos.

Pelo exposto reconhecemos haver inúmeras evidências contundentes de retroalimentação dos modus operandi e modus vivendi em operação nos muitos níveis performativos e discursivos a manutenir a face hegemônica de nossa cultura, nos seios familiares e das instituições, enfim, nas variadas relações próprias das sociedades humanas concorrendo com outras performatividades e discursividades dispostas a dialogarem a respeito destas mesmas e igualmente possíveis faces que, por minoritárias, em operação, subvertem a lógica massificada inscrita nesta mesma cultura. E é nesta intersecção o campo favorável à educação sexual já nos primeiros anos escolares, com especial atenção aos respectivos representantes de dois dos elos desta corrente, dispositivo escolar e as crianças.

As crianças têm consigo ao menos três caraterísticas de seu desenvolvimento interessantes ao processo educativo: aculturação inicial, plasticidade neuronal e a curiosidade. Estes três elementos característicos, temperam a infância a predispondo a recepcionar novas informações com menos resistência que uma pessoa jovem, adulta ou madura. De modo análogo ao terreno fértil que recebe as sementes, lhes favorecendo a germinação, a criança abrese mais facilmente ao novo, ao que lhe provoca e aguça sua curiosidade, seu querer e sua vontade. Ao dispositivo escolar, cabe a generosa solicitude, tal qual o agricultor que, cônscio de sua responsabilidade diante da terra que cultiva se dispõe a cuidar dela, entendendo não depender inteiramente de si o sucesso da colheita, porquanto ficar recostado à cadeira de balanço posta à varanda e contemplar a vastidão de suas terras, será modo certo para o silo vazio.

A responsabilidade do dispositivo escolar em favorecer o contato mediado, cientificamente alicerçado e eticamente respaldado em suas práticas no que diz respeito à temática da sexualidade diz não só da apropriação de informações sobre gêneros e suas relações sociais, mas da aculturação em favor do reconhecimento da criança por ela mesma em meio à complexidade das relações sociais e, também, de sua face violadora. Educar em sexualidade é, também, favorecer o reconhecimento do corpo da criança pela própria criança e seus limites e os limites do outro na relação com ela. A educação sexual, especialmente na infância, favorece 
que a criança entenda a importância do limite na, e da, intervenção do adulto na relação com o corpo infantil. Nas palavras de Sánchez e Pérez (1996 apud MAIA, 2005, p. 146-147)

As crianças realmente são vítimas fáceis porque justamente carecem de informações e habilidades que as facilitem poder defender-se a tempo. Pensamos que já se esperou muito tempo para se tomar alguma atitude, agora não podemos permitir que o silêncio continue; já são demais as vítimas. Por que oferecer Educação Sexual e assim prevenir o abuso sexual infantil? Já é hora de falar sobre como nascem os bebês, como são diferentes as meninas dos meninos, como é o abuso sexual e como dizer não ao abuso. Não permitam que estranhos ensinem as crianças de forma enviesada ou errada algo tão delicado... não esperem que seu filho ou filha seja vítima de abuso sexual para depois buscar este tipo de ajuda ou se este já ocorreu, ele voltará a ocorrer se não houver prevenção.

Sobre este assunto Maia (2005, p. 147-148), nos coloca que

É arriscado dizer que seja totalmente possível prevenir a ocorrência de um abuso sexual, mas certamente é desejável e necessário. Pais e educadores devem conversar com seus filhos e alunos, esclarecendo o que é o abuso sexual. Seria muito bom se não tivéssemos que falar sobre isso, ou sobre doenças sexualmente transmissíveis e outras consequências ruins relacionadas à sexualidade, mas é errado omitir essas coisas das crianças, pois se tiverem esclarecimento elas têm boas chances de evita-las.

O grande desafio consiste em tornar as crianças mais capazes de identificar a situação de abuso como uma situação inadequada. Isso, eventualmente, só acontece tarde demais, uma vez que o abusador, em geral, é uma pessoa conhecida, que pode seduzi-la e enganá-la. Como uma criança pode compreender o abuso sexual como algo errado quando isso acontece com alguém que ela conhece, confia e ama? Como, então, prevenir o abuso sexual? Alguns elementos chave estão presentes em praticamente todas as situações de abuso: o toque, que nem sempre é indesejado por ela (é preciso lembrar que ela também tem prazer quando alguém toca seus genitais), e principalmente, ameaças e pedidos de segredo. É preciso orientá-las e ensinálas a diferenciar um diálogo aberto sobre sexo de um toque indesejado de uma pessoa mais velha ou um adulto, seguido de ameaças e pedidos de segredo.

\section{Considerações finais}

Destarte é patente o desafio enfrentado cotidianamente no combate ao abuso sexual infantil e dificilmente se logrará êxito sem o concurso responsável e ético do dispositivo escolar, da família ou responsáveis e das crianças, estando a escola em posição de colaborar para viabilização do contato pela família e as crianças com este tema tabu e necessário de ser falado sobre: a sexualidade. Como nosso objetivo neste artigo é a análise da contribuição da Educação Sexual infantil, consideramos ter possibilitado algumas contribuições para a reflexão desta temática tão importante. 
Pelo exposto e dada a complexidade da temática do abuso sexual infantil, entendida aqui como toda carícia e manipulação genital, anal ou da mama com finalidade sexual, sem ou com penetração, bem como o voyeurismo, exibicionismo visando a gratificação sexual de pessoa adulta ou jovem mais velha, é importante lembramos que a pessoa agressora e/ou violadora costuma ser membro da própria família ou pessoa com quem a criança convive ou ainda alguém que frequenta o círculo familiar. Portanto, esta realidade é mais próxima do que se possa imaginar. Por isso mesmo, a educação sexual eticamente responsável e socialmente crítica deve se iniciar o quanto mais cedo possível e, melhor com o envolvimento de toda a comunidade, famílias e etc., participando deste processo favorável ao mesmo tempo pela autopercepção e autocuidados da criança consigo mesma, por qualificar adequadamente as conversas sobre esta temática tabu em nossa cultura e por possibilitar espaço oportuno para expressão das angústias dos responsáveis.

\section{REFERÊNCIAS}

AUGUSTINI, E. R. N.; ROSSI, C. R. A percepção do corpo feminino e masculino através do olhar das crianças: uma experiência em sala de aula. Revista Ibero-Americana de Estudos em Educação, Araraquara, p. 1623-1640, jan. 2016. ISSN 1982-5587. DOI: https://doi.org/10.21723/riaee.v10i6.8340

BRASIL. Constituição, 1988. Constituição: República Federativa do Brasil. Brasília: Senado Federal, 1988.

BRASIL. Decreto Presidencial n. 99.710/90. Convenção Internacional sobre os Direitos da Criança, aprovada pela Assembleia Geral das Nações Unidas. Artigo 27. 1. Os Estados Partes reconhecem o direito de toda criança a um nível de vida adequado ao seu desenvolvimento físico, mental, espiritual, moral e social. 1990.

BRASIL. Lei n. 8.069, de 13 de julho de 1990. Estatuto da Criança e do adolescente. Diário Oficial da União: Seção 1, Brasília, DF, p. 13563, 16 jul. 1990. PL 5172/1990

BUTLER, J. Corpos que importam: os limites discursivos do "sexo". Trad. Verônica Daminelli e Daniel Yago Françoli. São Paulo: n-1 edições; Crocodilo Edições, 2019.

BUTLER, J. Problemas de gênero: Feminismo e Subversão da Identidade. Rio de Janeiro: Civilização Brasileira, 2003.

FERNANDES, K. N. N.; REINA, F. T.; MOKWA, V. M. N. F. A música na sala de aula: reflexões sobre sexualidade na educação básica. Revista Ibero-Americana de Estudos em Educação, Araraquara, p. 1661-1672, jan. 2016. ISSN 1982-5587. DOI: https://doi.org/10.21723/riaee.v10i6.8342 
FOUCAULT, M. A história da sexualidade I: a vontade de saber. Rio de Janeiro: Graal, 1998.

GRAÇA, R. Performatividade e política em Judith Butler: corpo, línguagem e reivindicação de direitos. Revista Perspectiva Filosófica, Recife, v. 43, n. 1, set. 2016. ISSN 2357-9986. Disponível em: https://periodicos.ufpe.br/revistas/perspectivafilosofica/article/view/230291. Acesso em: 9 fev. 2020.

LUCIFORA, C. A. et al. Marcas sociais de nossos tempos: gênero, sexualidade e educação em âmbito escolar. Revista Ibero-Americana de Estudos em Educação, Araraquara, p. 1395-1409, jun., 2019. ISSN 1982-5587. DOI: https://doi.org/10.21723/riaee.v14iesp.2.12607

MAIA, A. C. B.; MAIA, A. F. (Org.). Caderno CECEMCA-Unesp, Bauru, v. 1, 2005. ISBN: 85-99703-01-3.

MEDEIROS, J. B. Redação cientifica: a prática de fichamentos, resumos, resenhas. São Paulo: Atlas, 2000.

MINAYO, M. C. S. (Org.). Pesquisa social: teoria, método e criatividade. Petrópolis, RJ: Vozes, 2003.

ONU. Organização das Nações Unidas. Declaração dos Direitos Humanos. 1948.

RIBEIRO, P. R. M.; MONTEIRO, S. A. S. Avanços e retrocessos da educação sexual no Brasil: apontamentos a partir da eleição presidencial de 2018. Revista Ibero-Americana de Estudos em Educação, Araraquara, p. 1254-1264, jun., 2019. ISSN 1982-5587. DOI: https://doi.org/10.21723/riaee.v14iesp.2.12701

SANTOS, B. R. Guia escolar: identificação de sinais de abuso e exploração sexual de crianças e adolescentes. Seropédica, RJ: EDUR, 2011.

ZOCCA, A. R. et al. Percepções de adolescentes sobre sexualidade e educação sexual. Revista Ibero-Americana de Estudos em Educação, Araraquara, p. 1463-1476, jan. 2016. ISSN 1982-5587. DOI: https://doi.org/10.21723/riaee.v10i6.8331

\section{Como referenciar este artigo}

NETO, A. A. F. L.; JACINTO, J. C.; DESIDÉRIO, R. A curiosidade denegada: quando a infância negligenciada favorece o risco ao abuso sexual. Revista on line de Política e Gestão Educacional, Araraquara, v. 24, n. esp. 3, p. 1713-1726, dez. 2020. e-ISSN:1519-9029. DOI: https://doi.org/10.22633/rpge.v24iesp3.14275

Submetido em: 10/08/2020

Revisões requeridas: $20 / 10 / 2020$

Aprovado em: 05/11/2020

Publicado em: $30 / 11 / 2020$ 